\title{
Meutldak poetik.
}

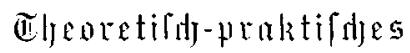

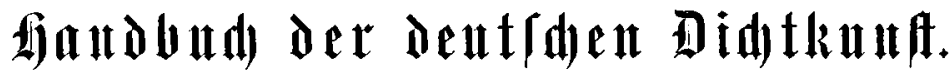

\author{
Itarty Den Anforderungen Der Gegermort \\ bot \\ Wrof. Dr. (T. B $\mathfrak{e} \mathfrak{y} \mathfrak{e}$ r.
}

Bueite :aflage.

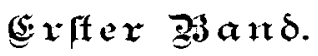

$S \mathfrak{d} \mathfrak{t} \mathfrak{t} \mathfrak{g} \mathfrak{a} \mathfrak{r} t$.

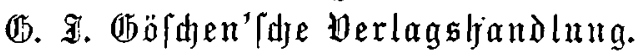
1887. 
f. (19ofbudjoruckerei Ba (bntterberg (er. O5rïninger) in Stuttgart. 